\title{
Isolation and characterization of $N g R L K 1$, a receptor-like kinase of Nicotiana glutinosa that interacts with the elicitin of Phytophthora capsici
}

\author{
Yeong-Tae Kim · Jonghee Oh $\cdot$ Kyung-Hwan Kim • \\ Jae-Youl Uhm · Byoung-Moo Lee
}

Received: 23 September 2008/Accepted: 1 May 2009/Published online: 16 May 2009

(c) The Author(s) 2009. This article is published with open access at Springerlink.com

\begin{abstract}
Elicitins, extracellular proteins from Phytophthora fungi, elicit a hypersensitivity response (HR), including systemic acquired resistance, in some plants. The elicitin capsicein $(\sim 10 \mathrm{kDa})$ was purified by FPLC from culture filtrates of $P$. capsici. Purified native and recombinant capsicein induced a hypersensitive response in leaves of the non-host plants Nicotiana glutinosa and Brassica rapa subsp. pekinensis. To search for candidate capsicein-interacting proteins from $N$. glutinosa, a yeast two-hybrid assay was used. We identified a protein interactor that is homologous to a serine/threonine kinase of the plant receptor-like kinase (RLK) group and designated it $N g R L K 1$. The ORF of $N g R L K 1$ encodes a polypeptide of 832 amino acids $(93,490 \mathrm{Da})$. A conserved domain analysis revealed that $\mathrm{NgRLK} 1$ has structural features typical of a plant RLK. NgRLK1 was autophosphorylated, with higher activity in the presence of $\mathrm{Mn}^{2+}$ than $\mathrm{Mg}^{2+}$.
\end{abstract}

Keywords Phytophthora capsici - Elicitin - Capsicein . $\mathrm{HR} \cdot \mathrm{RLK} \cdot N g R L K 1$

Yeong-Tae Kim and Jonghee Oh have contributed equally to this work and should be considered as joint first authors.

Y.-T. Kim $(\bowtie) \cdot$ J. Oh $(\bowtie) \cdot$ K.-H. Kim · B.-M. Lee National Institute of Agricultural Science, Rural Development Administration, Suwon 441-707, Korea

e-mail: ytkim33@rda.go.kr

J. Oh

e-mail: jake92@unitel.co.kr

J.-Y. Uhm

Division of Applied Biology and Chemistry, Kyungpook

National University, Daegu 702-701, Korea

\section{Introduction}

Fungi of the genus Phytophthora are a major cause of crop destruction. Root rot caused by Phytophthora capsici soil infection is a serious disease affecting the cultivation of red pepper [1], and Phytophthora blight of pepper caused by this pathogen is one of the most destructive soilborne diseases in Korea [2]. Many Phytophthora produce elicitins, members of a family of small extracellular proteins that cause a hypersensitive response associated with the defense response of Nicotiana and Brassica species [3]. Elicitins are conserved, 98-amino acid ( $\sim 10 \mathrm{kDa})$ holoproteins that are abundantly secreted into the medium [4-7].

Elicitin genes and proteins have been cloned and purified from many species, including $P$. parasitica [8], P. cryptogea [9], P. sojae [10, 11], P. infestans [12], and $P$. cinnamomi [13], although the elicitin gene from P. capsici has not yet been cloned. All known Phytophthora elicitins show $>60 \%$ sequence identity [4]. Elicitins from different fungal species cause necrotic lesions on tobacco, but plant defense reactions are induced at the same level [5]. The major 98-amino acid elicitins of Phytophthora have been divided into acidic $(\alpha)$ - and basic $(\beta)$-elicitins $[14,15]$. The $\beta$-elicitins produce greater necrosis than the $\alpha$-elicitins, and the difference in biological activity is correlated with differences in sequence and physico-chemical features among them [4, 16, 17]. Kamoun et al. have proposed dividing the elicitins and elicitin-like proteins of Phytophthora and Pythium species into five classes based on phylogenic analysis and the overall structures of the proteins [12]. Jiang et al. searched for new elicitin and elicitin-like gene family members by making use of a Phytophthora expressed sequence tag (EST) database and classified all family members of elicitin based on sequence and protein motifs [18]. 
Although elicitins are thought to be major determinants of non-host resistance against Phytophthora infection in Nicotiana species [5, 19], the role of elicitins in the biology of Phytophthora are not clear, and little is known about the molecular mechanisms involved in elicitin activity. Specific, high-affinity binding sites for $\beta$-cryptogein of $P$. cryptogea were observed in tobacco plasma membranes [20], but these proteins did not exhibit any protease, $\beta$-glucanase, or phospholipase activity, and no other enzymatic activity has been reported for them [3, 21]. One likely biological role for elicitins is as sterol scavengers, because they are known to be sterol carrier proteins and Phytophthora species do not synthesize sterols [22].

Elicitins are known to be secreted by Phytophthora species and have been assumed to localize in the extracellular space of plant tissue. Consequently, it is conceivable that elicitins interact with a host molecule in the plant plasma membrane to initiate plant cell responses following elicitin recognition. Despite the identification of many elicitin proteins, membrane receptors for elicitins have not been clearly identified to date. In a yeast two-hybrid assay, Tyler (unpublished data) found a tobacco cDNA encoding an intracellular elicitin-binding protein, which contained a nucleotide-binding site and leucine-rich repeat motifs [3]. The protein expressed from this cDNA was required for the elicitin response in tobacco, but its expression in tomato or petunia did not result in gain of an elicitin response in those plants. Tyler suggested that additional membrane receptor proteins may be required for the elicitin response. Kanzaki et al. isolated and characterized NbLRK1, which is a $P$. infestans INF1 elictin-interactor from $N$. benthamiana [23]. In their study, INF1 was found to bind to the intracellular domain (kinase domain) of NbLRK1. Therefore, they speculated that plant recognition of INF1 takes place inside the plant cells.

In this paper, we report the molecular cloning and protein purification of the elicitin from $P$. capsici. In addition, we used a yeast two-hybrid assay to identify a capsiceininteracting protein from tobacco, N. glutinosa. Sequence analysis revealed that the capsicein-interacting protein, designated NgRLK1, has domains typical of plant receptorlike kinases (RLKs). The kinase domain of NgRLK1 was expressed in Escherichia coli, and this domain was autophosphorylated in the presence of $\mathrm{Mn}^{2+}$ or $\mathrm{Mg}^{2+}$.

\section{Materials and methods}

Strains, plasmids, and growth conditions

The Phytophthora, E. coli, and yeast strains and the plasmids used in this study are described in Table 1. The Phytophthora strain was grown at $24^{\circ} \mathrm{C}$ in cleared or uncleared $20 \%$ vegetable juice (V8) medium supplemented with $1.5 \%$ agar. For elicitin production, the strains were grown for 3 weeks at $28^{\circ} \mathrm{C}$ in still culture in a synthetic medium containing (per liter): $0.5 \mathrm{~g}$ of $\mathrm{KH}_{2} \mathrm{PO}_{4}, 0.25 \mathrm{~g}$ of $\mathrm{MgSO}_{4} \cdot 7 \mathrm{H}_{2} \mathrm{O}, 1 \mathrm{~g}$ of asparagine, $1 \mathrm{mg}$ of thiamine, $0.5 \mathrm{~g}$ of yeast extract, and $25 \mathrm{~g}$ of glucose [17]. The E. coli strains were cultured in Luria-Bertani (LB) medium (USB) at $37^{\circ} \mathrm{C}$, and the yeast cultures were grown at $30^{\circ} \mathrm{C}$ in either YPDA (1\% yeast extract, $2 \%$ peptone, $2 \%$ glucose, and $0.2 \%$ adenine) or SD (minimal synthetic dropout) medium (Clontech) with dropout (DO) supplements (Clontech) according to the auxotrophies of the yeast strains. The antibiotics used in this study were ampicillin (100 $\mu \mathrm{g} / \mathrm{ml}$, Duchefa) and kanamycin (50 $\mu \mathrm{g} / \mathrm{ml}$, Sigma).

Isolation and purification of capsicein

Three weeks after inoculation, culture filtrates of $P$. capsici $\mathrm{Pa} 28$ were harvested through triple layers of Miracloth and centrifuged at $6,000 \mathrm{~g}$ for $30 \mathrm{~min}$. The supernatant was filtered through a $0.8-\mu \mathrm{m}$ filter and was brought to $95 \%$ saturation by adding ammonium sulfate with stirring at $4^{\circ} \mathrm{C}$ for $16 \mathrm{~h}$. The precipitated proteins were collected by centrifugation $(6,000 \mathrm{~g}$ for $30 \mathrm{~min})$. The protein pellet was resuspended in $10 \mathrm{mM}$ Tris- $\mathrm{HCl}(\mathrm{pH} \mathrm{7.0)}$ and was dialyzed against the same buffer to remove the ammonium sulfate. After dialysis, capsicein was purified by Fast Protein Liquid Chromatography (FPLC) using a Superdex 200 HR 10/30 column (GE Healthcare Bioscience AB) in $10 \mathrm{mM}$ Tris- $\mathrm{HCl}$ ( $\mathrm{pH}$ 7.0). The concentration of the purified capsicein was determined by the Bradford method (Bio-Rad) using BSA as a standard. The protein was visualized on $15 \%$ SDS-polyacrylamide gels stained with Coomassie Brilliant Blue (CBB) R-250 (Sigma).

N-terminal amino acid sequencing

After electrophoresis of the purified capsicein, the protein was transferred onto a PVDF membrane (Applied Biosystems) in $10 \mathrm{mM}$ CAPS (Sigma) buffer under a constant current of $200 \mathrm{~mA}$ for $1 \mathrm{~h}$. To confirm the transfer, the membrane was stained for a few seconds with $0.1 \% \mathrm{CBB}$ R-250 (Sigma) in 1\% acetic acid/40\% methanol and then destained with $50 \%$ methanol. The capsicein on the membrane was sequenced by automated Edman degradation performed by an Applied Biosystem 476A sequencer (Applied Biosystems) using the reagents and methods supplied by the manufacturer.

Cloning of the capsicein gene

Standard methods were used for DNA/RNA manipulation, DNA cloning, and gel electrophoresis [24]. The capsicein 
Table 1 Bacterial strains and plasmids

\begin{tabular}{|c|c|c|}
\hline Strains/plasmids & Characteristics $^{\mathrm{a}}$ & Sources/references \\
\hline \multicolumn{3}{|l|}{ Strains } \\
\hline \multicolumn{3}{|l|}{ Escherichia coli } \\
\hline DH5 $\alpha$ & $\begin{array}{l}\mathrm{F}^{-} \text {Ф80dlacZAM15 } \Delta(\text { lacZYA-argF }) U 169 \text { endA1 deoR recA1 hsdR17 }\left(\mathrm{r}_{\mathrm{K}}{ }^{-} \mathrm{m}_{\mathrm{K}}{ }^{+}\right) \text {phoA } \\
\quad \text { supE44 } \lambda^{-} \text {thi-1 gyrA96 relA1 }\end{array}$ & Gibco-BRL \\
\hline BL21 & $\mathrm{F}^{-}$ompT hsdS $S_{B}\left(\mathrm{r}_{\mathrm{B}}^{-} \mathrm{m}_{\mathrm{B}}^{+}\right)$gal dcm & Takara \\
\hline BL21(DE3) & $\mathrm{F}^{-}$ompT hsdS ${ }_{B}\left(\mathrm{r}_{\mathrm{B}}^{-} \mathrm{m}_{\mathrm{B}}^{+}\right)$gal dcm $\lambda(\mathrm{DE} 3)$ & Novagen \\
\hline Top10 & $\begin{array}{l}\mathrm{F}^{-} m c r \mathrm{~A} \Delta(m r r-h s d \mathrm{RMS}-m c r \mathrm{BC}) \text { (80lacZ } \Delta \mathrm{M} 15 \Delta \text { lac } \mathrm{X} 74 \text { rec } \mathrm{A} 1 \text { ara } \mathrm{D} 139 \\
\quad \Delta(\text { ara-leu }) 7697 \text { galU galK } r p s \mathrm{~L}\left(\mathrm{Str}^{\mathrm{R}}\right) \text { end } \mathrm{A} 1 \text { nup } \mathrm{G}\end{array}$ & Invitrogen \\
\hline \multicolumn{3}{|c|}{ Saccharomyces cerevisiae } \\
\hline AH109 & 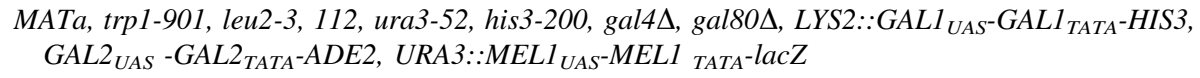 & Clontech \\
\hline \multicolumn{3}{|c|}{ Phytophthora capsici } \\
\hline $\mathrm{Pa} 28$ & Wild type (a Korean isolate) & NIAST, RDA ${ }^{\mathrm{b}}$ \\
\hline \multicolumn{3}{|l|}{ Plasmids } \\
\hline pGEX-2T & tac promoter-based expression vector; $A m p^{r}$ & $\begin{array}{l}\text { GE Healthcare } \\
\text { Bioscience }\end{array}$ \\
\hline pGEX4T-1 & tac promoter-based expression vector; $\mathrm{Amp}^{\mathrm{r}}$ & $\begin{array}{l}\text { GE Healthcare } \\
\text { Bioscience }\end{array}$ \\
\hline pCR4.1-TOPO & Cloning and sequencing vector; $A m p^{r}$ & Invitrogen \\
\hline pGEM-T easy & Cloning and sequencing vector; $A m p^{r}$ & Promega \\
\hline pGADT7-Rec & AD/library, LEU2, HA epitope; $\mathrm{Amp}^{\mathrm{r}}$ & Clontech \\
\hline pGADT7 & AD/library, LEU2, HA epitope; $\mathrm{Amp}^{\mathrm{r}}$ & Clontech \\
\hline pGBKT7 & DNA/bait, $T R P 1$, c-Myc epitope; $\mathrm{Km}^{\mathrm{r}}$ & Clontech \\
\hline pGADT7-T & $\mathrm{AD} / \mathrm{T}$-antigen, control vector (yeast-two hybrid); $\mathrm{Amp}^{\mathrm{r}}$ & Clontech \\
\hline PGBKT7-53 & DNA-BD/p58, control vector (yeast-two hybrid); $\mathrm{Km}^{\mathrm{r}}$ & Clontech \\
\hline pCold $^{\mathrm{TM}} \mathrm{II}$ & $\operatorname{csp} \mathrm{A}$ promoter-based cold shock expression vector; $\mathrm{Amp}^{\mathrm{r}}$ & Takara \\
\hline pGEMCAP1 & Cap-Pa28 in pGEM-T Easy; $\mathrm{Amp}^{\mathrm{r}}$ & This study \\
\hline pGEXCAP1 & Cap-Pa28 in pGEX-2T; $\mathrm{Amp}^{\mathrm{r}}$ & This study \\
\hline pBDCAP1 & Cap-Pa28 in pGBKT7; $\mathrm{Km}^{\mathrm{r}}$ & This study \\
\hline pADNG-238 & $\begin{array}{l}\text { 2,749 bp cDNA fragment including entire } N g R L K 1 \text { from } N \text {. glutinosa } \\
\text { cloned into pGADT7-Rec; } A^{\mathrm{r}}{ }^{\mathrm{r}}\end{array}$ & This study \\
\hline pAD-RLK1 & $N g R L K 1$ in pGADT7; $\mathrm{Amp}^{\mathrm{r}}$ & This study \\
\hline pAD-RLK1out & $N g R L K 1^{23-438}$ in pGADT7; $\mathrm{Amp}^{\mathrm{r}}$ & This study \\
\hline PAD-RLK11n & $N g R L K 1^{522-789}$ in pGADT7; $\mathrm{Amp}^{\mathrm{r}}$ & This study \\
\hline pGX4-RLK1in & $N g R L K 1^{522-789}$ in pGEX4T-1; Amp ${ }^{\mathrm{r}}$ & This study \\
\hline pCD-RLK1out & $N g R L K 1^{23-438}$ in pCold ${ }^{\mathrm{TM}} \mathrm{II} ; \mathrm{Amp}^{\mathrm{r}}$ & This study \\
\hline pCD-RLK1in & $N g R L K 1^{522-789}$ in pCold ${ }^{\mathrm{TM}} \mathrm{II} ; \mathrm{Amp}^{\mathrm{r}}$ & This study \\
\hline
\end{tabular}

${ }^{a} \mathrm{Amp}^{\mathrm{r}}$, ampicillin resistance; $\mathrm{Km}^{\mathrm{r}}$, kanamycin resistance

b National Institute of Agricultural Science and Technology, Rural Development Administration

gene from $P$. capsici was cloned by a reverse transcriptionpolymerase chain reaction (RT-PCR). Total $P$. capsici RNA was obtained by phenol-chloroform extraction of 3-week-old mycelia in liquid culture [24], and $1 \mu \mathrm{g}$ of total RNA was used as the template for RT-PCR with 100 pmol of degenerate primers, dCap-F (5'-ACVCARCARACVG CMGCMTA- $3^{\prime}$ ) and dCap-R (5'-GCRCABGTKGCYG ARAADCCRTT- $3^{\prime}$ ), that were designed based on the alignment of the amino acid sequence determined for capsicein and the sequences of conserved domains of known elicitins taken from the ExPASy database (www.expasy.org). The synthesis of capsicein cDNA was performed using an RNA PCR kit (AMV) Ver 2.1 (Takara) according to the manufacturer's instructions. Amplification was performed for 30 cycles of $30 \mathrm{~s}$ each denaturation at $94^{\circ} \mathrm{C}$, annealing at $55^{\circ} \mathrm{C}$ for $40 \mathrm{~s}$, and extension at $72^{\circ} \mathrm{C}$ for 
$1 \mathrm{~min}$. The PCR product was gel purified and cloned into pGEM-T Easy vector (Promega) for sequencing by an ABI Prism 3100 automated DNA sequencer (Applied Biosystems). The nucleotide and amino acid sequences were analyzed using the BLASTX program (http://ncbi.nlm.nih. gov/BLAST, http://www.expasy.org/tools).

\section{Expression of capsicein in E. coli}

For construction of the glutathione S-transferase (GST)capsicein fusion protein expression plasmid, the capsicein gene was amplified from capsicein cDNA by PCR using the primers Cap-Pa28F (5'-CGGGATCCATGATTGCA GAACAAAGACTACAT-3') and Cap-Pa28R (5'-CCG CTCGAGTTACCTTGGTCCAGATAAAACTGA-3'). The PCR product was digested with BamHI and EcoRI, followed by cloning into the corresponding sites of pGEX-2T vector containing the GST gene (GE Healthcare Bioscience $\mathrm{AB})$. The E. coli BL21(DE3) strain harboring the cloned gene in pGEX-2T was grown in LB, and expression of the GST-capsicein fusion protein was induced with $0.5 \mathrm{mM}$ IPTG at $37^{\circ} \mathrm{C}$ for $4 \mathrm{~h}$. The cells were harvested by centrifugation and resuspended in $20 \mathrm{mM}$ Tris- $\mathrm{HCl}(\mathrm{pH} 7.5)$, $10 \mathrm{mM}$ EDTA, and $1 \%$ Triton X-100. The bacterial suspension was sonicated with a VCX-400 sonicator (Sonics \& Materials Inc.) to lyse the cells. The insoluble protein was collected by centrifugation $(13,000 \mathrm{~g}$ for $10 \mathrm{~min})$, solubilized using a CAPS buffer at alkaline $\mathrm{pH}$ in combination with N-lauroylsarcosine, and refolded using a protein refolding kit (Novagen). The refolded fusion protein was purified by glutathione Sepharose 4B affinity chromatography (GE Healthcare Bioscience $\mathrm{AB}$ ) in PBS buffer, followed by GST cleavage (on-column) with thrombin $(80 \mathrm{U})$ during $14 \mathrm{~h}$ at $24^{\circ} \mathrm{C}$.

\section{Hypersensitivity response (HR) assay}

Induction of hypersensitivity by capsicein was determined by petiole dip assays [25]. Leaf petioles of freshly cut leaves of N. glutinosa and Brassica rapa subsp. pekinensis were dipped into a $50 \mathrm{ml}$ sterile distilled water solution of capsicein. The solution was taken up after $2 \mathrm{~h}$. Then leaves were transferred to sterile water. Necrotic lesions were visible after $24-48 \mathrm{~h}$.

Yeast two-hybrid assay

Yeast two-hybrid screening was performed according to the manufacturer's instructions (BD Matchmaker Library Construction \& Screening kits, BD Biosciences Clontech). The PCR-amplified capsicein coding region was cloned into the binding-domain (BD) vector pGBKT7 as bait. A $N$. glutinosa activation domain (AD) fusion cDNA library was prepared from total RNA extracted from leaves of N. glutinosa. Competent AH109 yeast cells were co-transformed with combinations of the bait plasmid pGBKT7capsicein, the AD fusion library cDNA, and the linearized activation-domain vector pGADT7-Rec using the LiAc/ PEG method. The co-transformants were plated onto minimal medium lacking Ade, His, Leu and Trp and containing $10 \mathrm{mM}$ 3-amino-1, 2, 4-triazole. The plates were incubated at $30^{\circ} \mathrm{C}$ for $3-5$ days, and yeast colonies that grew on the dropout (DO) medium were sub-cultured onto the same medium containing $\mathrm{X}-\alpha-\mathrm{Gal}$ and assayed for $\mathrm{X}-\alpha$-galactosidase activity using a filter-lift assay. Positive control was produced by co-transformation with pGADT7-T (Clontech), which expresses murine $\mathrm{p} 53$ fused with the GAL4 DNA BD and pGBKT7-p53 (Clontech), expressing the SV40 large T-antigen fused to the GAL $4 \mathrm{AD}$. The cDNA fragments in pGADT7-Rec isolated from positive colonies of the $\mathrm{X}-\alpha$ galactosidase assay were sequenced, and the cDNA sequence data were analyzed using the BLAST X search of NCBI. Interactions of NgRLK1 and extracelluar and cellular domains of NgRLK1 with CAP-Pa28 were tested under the same experimental conditions as described above. $N g R L K 1^{23-789}, N g R L K 1^{23-438}$ and $N g R L K 1^{522-789}$ were inserted into pGADT7 (BD Biosciences Clontech) as prey. Yeast transformants harboring bait and prey constructs were plated onto minimal medium containing $\mathrm{X}-\alpha-\mathrm{Gal}$ without Ade, His, Leu and Trp.

Rapid amplification of cDNA ends (RACE)

for full-length $N g R L K 1 \mathrm{cDNA}$, and sequence analysis

Total RNA $(1 \mu \mathrm{g})$ from leaves of $N$. glutinosa was used as the template. Forward and reverse gene-specific primers (GSPs) were designed based on the sequence of the putative interactor cDNA identified in the yeast two-hybrid screening. RACE was carried out using a SMART RACE cDNA amplification kit (Clontech). PCR was performed on a PE GeneAmp system 9600 (Applied Biosystems) under the following conditions: denaturation at $94^{\circ} \mathrm{C}$ for $2 \mathrm{~min}$; 30 cycles of $94^{\circ} \mathrm{C}$ for $5 \mathrm{~s}, 68^{\circ} \mathrm{C}$ for $10 \mathrm{~s}$, and $72^{\circ} \mathrm{C}$ for $3 \mathrm{~min}$; and a final extension at $72^{\circ} \mathrm{C}$ for $10 \mathrm{~min}$. The PCR product was cloned into TOPO TA vector (Invitrogen) and sequenced. Sequence alignments and open-reading frame translations were performed on DNASTAR 5.05. BLAST analyses of the nucleotide and protein sequences were conducted using programs at the ExPASy (http://www. expasy.org) and NCBI (http://ncbi.nlm.nih.gov/BLAST) websites. The protein structure was predicted as described previously $[26,27]$ using programs on the SMART website (http://smart.embl-heidelberg.de). The protein-based phylogenetic analysis of NgRLK1 was conducted using 
the PhyML program at Phylogeny.fr server (http://www. phylogeny.fr).

\section{GST-pull-down assays}

The CAP-Pa28 and NgRLK1 interaction was determined by GST-pull-down assay using the ProFound ${ }^{\mathrm{TM}}$ Pull-down GST Protein:Protein interaction kit (Pierce), as described by the manufacturer. For the preparation of prey proteins, pCold ${ }^{\mathrm{TM}}$ II vectors (Takara) containing the cDNA coding sequence for the extracellular domain $\left(\mathrm{NgRLK} 1^{23-438}\right)$ and the cellular domain (NgRLK1 $\left.{ }^{522-789}\right)$ of $N g R L K 1$ were transformed into $E$. coli BL21. The coding sequences of the extracellular and cellular domains were amplified by PCR using $N g R L K 1$ cDNA as the template and the PCR primer sets RLK1out-F (5'-ATTCCATATGGCTATATCCCAAA TTTC- $\left.3^{\prime}\right)$ and RLK1out-R (5'-CGGGATCCTTACACC TTAAGAAATACT-3') for the extracellular domain, and RLK1in-F (5'-AATTCCATATGGATTTCAGCACAAAG CTT- $\left.3^{\prime}\right)$ and RLK1in-R (5'-CGGGATCCTTACAGTGCC TTAACCACC $-3^{\prime}$ ) for the cellular domain. The PCR products were cloned into the $N d e \mathrm{I} / \mathrm{BamHI}$ sites of the pCold ${ }^{\mathrm{TM}}$ II vector. The transformants were grown in LB, and expression of the His-tagged NgRLK1 $1^{23-438}$ and NgRLK $1^{522-789}$ was induced with $0.1 \mathrm{mM}$ IPTG at $15^{\circ} \mathrm{C}$ for $24 \mathrm{~h}$. The protein solubilization and refolding procedures were as described above. The refolded fusion protein was loaded onto a Ni-NTA spin column (Qiagen). His-tagged protein was bound to the Ni-NTA matrix by centrifugation at $1,000 \mathrm{~g}$ for $2 \mathrm{~min}$ at room temperature. The protein binding matrix was washed two times with washing buffer $(20 \mathrm{mM}$ imidazole, $20 \mathrm{mM}$ Tris- $\mathrm{HCl}, \mathrm{pH} 8.0$ ) to remove unbound protein. His-tagged protein was eluted with elution buffer (500 $\mathrm{mM}$ imidazole, $20 \mathrm{mM}$ Tris- $\mathrm{HCl}, \mathrm{pH} \mathrm{8.0)}$, and the eluted protein was dialyzed against $20 \mathrm{mM}$ Tris- $\mathrm{HCl}(\mathrm{pH}$ 8.0) to remove imidazole. The purified GST-CAP-Pa28 (bait protein) and parental GST (control) were immobilized on $50 \mu \mathrm{l}$ of glutathione-Sepharose beads, which were equilibrated with the PBS buffer ( $\mathrm{pH} 7.4$ ) in the Handee ${ }^{\mathrm{TM}}$ MiniSpin column (Pierce). Purified $\mathrm{His}_{6}-\mathrm{NgRLK} 1^{23-438}$ and $\mathrm{His}_{6}-\mathrm{NgRLK} 1^{522-789}$ were used as prey proteins to detect interactions with the bait protein. The bait-prey proteins were eluted by incubating the beads with $100 \mathrm{mM}$ glutathione for $10 \mathrm{~min}$ at $25^{\circ} \mathrm{C}$ and collected by centrifuging at $1,250 \mathrm{~g}$ for $1 \mathrm{~min}$ at $25^{\circ} \mathrm{C}$. Immunoblotting was used to detect $\mathrm{His}_{6}-\mathrm{NgRLK} 1^{23-438}$ and $\mathrm{His}_{6}-\mathrm{NgRLK} 1^{522-789}$ using anti$6 \times$ His tag antibody (Takara).

Autophosphorylation assay of the kinase domain of NgRLK1

For protein expression of the kinase domain of NgRLK1, the GST fusion protein expression vector pGEX4T-1 (GE
Healthcare Bioscience) was used. The kinase domain of NgRLK1 (NgRLK1 $\left.1^{522-789}\right)$ was amplified by PCR using $N g R L K 1$ cDNA as the template and specific PCR primers, rlkD-F (5'-CGGGATCCGATTTCAGCACAAAGCTTGG GGAA- $\left.3^{\prime}\right)$ and rlkD-R (5'-CCGCTCGAGCAGTGCCTTA ACCACCCATGTCAT- $3^{\prime}$ ). The PCR product was digested with BamHI and XhoI, followed by cloning into the corresponding sites of pGEX4T-1 vector. The $N g R L K 1^{522-789}$ DNA fragment in pGEX4T-1 was sequenced to confirm correct insertion, and the vector was introduced into $E$. coli BL21(DE3). The transformants were grown in LB containing ampicillin; when the culture reached an optical density of $0.6-0.8$ at $600 \mathrm{~nm}$, expression of the GST-capsicein fusion protein was induced with $1 \mathrm{mM} \mathrm{IPTG}$ at $37^{\circ} \mathrm{C}$ for $4 \mathrm{~h}$. The protein solubilization, refolding, and purification procedures were as described above. A gel-based autophosphorylation assay [28] was performed in a $20-\mu 1$ volume containing $1 \mu \mathrm{g}$ of GST-NgRLK1 ${ }^{522-789}$ protein, $25 \mathrm{mM}$ Hepes ( $\mathrm{pH} 7.5$ ), $10 \mathrm{mM} \mathrm{MnCl}_{2}$ or $\mathrm{MgCl}_{2}$, and $10 \mu \mathrm{Ci}$ $\left[\gamma_{-}{ }^{32} \mathrm{P}\right]$ ATP. After incubation at $30^{\circ} \mathrm{C}$ for $30 \mathrm{~min}$, the reaction was quenched by the addition of SDS-PAGE electrode buffer. The phosphorylated protein was separated by SDSPAGE, and the gel was exposed to a PhosphoImage screen (Fuji). The radioactivity incorporated into GSTNgRLK $1^{522-789}$ on the gel was detected using a Bio-Rad FX molecular imager system.

\section{Results}

Isolation and sequencing of capsicein CAP-Pa28

Capsicein was purified from $P$. capsici $\mathrm{Pa} 28$ culture medium by a one-step chromatographic procedure. We collected the fractions containing the single capsicein peak and confirmed the presence of a $10-\mathrm{kDa}$ protein band by SDS-PAGE analysis (Fig. 1a, b). The N-terminal amino acid sequence derived from the purified SDS-PAGE protein band was $\mathrm{NH}_{3}$-ATCTTTQQTAAYVALVSILSDSSFN-COOH, which matched the previously reported capsicein sequence [29]. This capsicein was named CAP-Pa28. Purified CAP-Pa28 induced a hypersensitive response (HR) in the leaves of N. glutinosa and B. rapa subsp. pekinensis (Fig. 1c) but not Capsicum annuum. We cloned the CAP-Pa28 gene by RT-PCR of total RNA extracted from $P$. capsici and degenerate primers based on conserved domains of known elicitins from Phytophthora, and sequenced the CAP-Pa28 clone (accession no. AF461432; Fig. 2). Similar to other Phytophthora elicitins, CAP-Pa28 comprises 98 amino acid residues, has a molecular weight of $10.16 \mathrm{kDa}$, and lacks Trp, His, and Arg. CAP-Pa28 has an acidic isoelectric point ( $\mathrm{pI}=4.23$ ), characteristic of the $\alpha$-elicitins. 


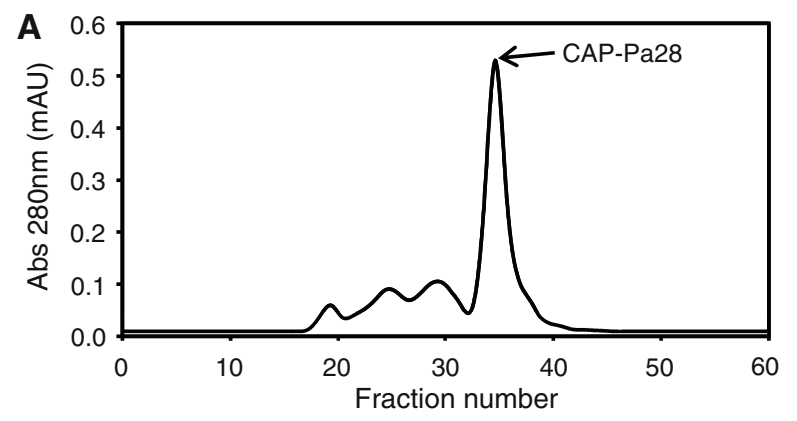

B

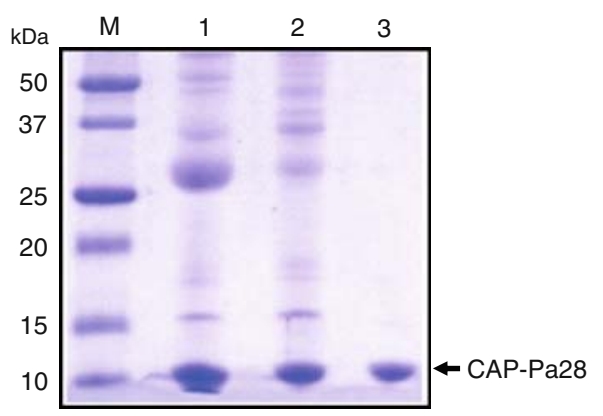

C Brassica rapa subsp. pekinensis

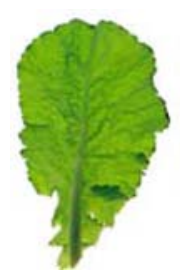

Control (10mM Tris- $\mathrm{HCl})$

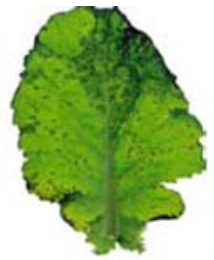

CAP-Pa28

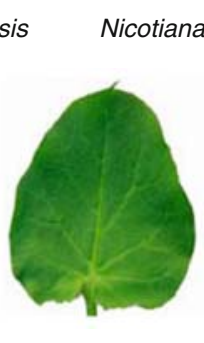

Control (10mM Tris- $\mathrm{HCl})$

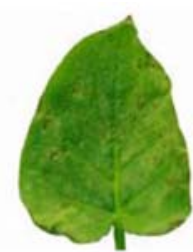

CAP-Pa28
Fig. 1 Purification of capsicein from P. capsici Pa28 and the induction of a hypersensitive response by CAP-Pa28. a Elution of capsicein from a Superdex $200 \mathrm{HR}$ gel filtration column. b SDSPAGE of capsicein, purified from culture filtrate. $\mathrm{M}$, molecular size markers; 1, dialyzed culture filtrate after $95 \%$ ammonium sulfate precipitation; 2 , after filtering through $0.2 \mu \mathrm{m}$ pore size membrane (Whatman); 3, CAP-Pa28 fraction from FPLC gel filtration. c The hypersensitive response induced in Brassica rapa subsp. pekinensis and Nicotiana glutinosa leaves by $50 \mathrm{nmol}$ of purified CAP-Pa28

1 GCCACGTGTACGACTACCCAGCAAACGGCCGCCTACGTCGCCCTGGTG 48

$\begin{array}{llllllllllllllllll}1 & \mathrm{~A} & \mathrm{~T} & \mathrm{C} & \mathrm{T} & \mathrm{T} & \mathrm{T} & \mathrm{Q} & \mathrm{Q} & \mathrm{T} & \mathrm{A} & \mathrm{A} & \mathrm{Y} & \mathrm{V} & \mathrm{A} & \mathrm{L} & \mathrm{V} & 16\end{array}$

49 AGCATCCTCTCGGACTCTTCGTTCAACCAGTGCGCCACGGACTCTGGC 96

$\begin{array}{llllllllllllllllll}17 & \mathrm{~S} & \mathrm{I} & \mathrm{L} & \mathrm{S} & \mathrm{D} & \mathrm{S} & \mathrm{S} & \mathrm{F} & \mathrm{N} & \text { Q } & \text { C } & \text { A } & \text { T } & \text { D } & \text { S } & \text { G } & 32\end{array}$

97 TACTCGATGCTGACGGCCACGGCGCTGCCCACGACGGCGCAGTACAAG 144

$\begin{array}{llllllllllllllllll}33 & \text { Y } & \text { S } & \text { M } & \text { L } & \text { T } & \text { A } & \text { T } & \text { A } & \text { L } & \text { P } & \text { T } & \text { T } & \text { A } & \text { Q } & \text { Y } & \text { K } & 48\end{array}$

145 CTCATGTGCGCGTCGACGGCGTGCAACACGATGATCACCAAGATCGTG 192

$\begin{array}{llllllllllllllllll}49 & \mathrm{~L} & \text { M } & \text { C } & \text { A } & \text { S } & \text { T } & \text { A } & \text { C } & \text { N } & \text { T } & \text { M } & \text { I } & \text { T } & \text { K } & \text { I } & \text { V } & 64\end{array}$

193 TCGCTGAACCCCCCTGACTGCGAGCTGACGGTGCCCACGAGCGGTCTG 240

$\begin{array}{llllllllllllllllll}65 & \mathrm{~S} & \mathrm{~L} & \mathrm{~N} & \mathrm{P} & \mathrm{P} & \mathrm{D} & \mathrm{C} & \mathrm{E} & \mathrm{L} & \mathrm{T} & \mathrm{V} & \mathrm{P} & \mathrm{T} & \mathrm{S} & \mathrm{G} & \mathrm{L} & 80\end{array}$

241 GTGCTCAACGTTTACTCGTACGCGAATGGATTTTCAGCAACATGCGCA 288

$\begin{array}{llllllllllllllllll}81 & \mathrm{~V} & \mathrm{~L} & \mathrm{~N} & \mathrm{~V} & \mathrm{Y} & \mathrm{S} & \text { Y } & \text { A } & \text { N } & \text { G } & \text { F } & \text { S } & \text { A } & \text { T } & \text { C } & \text { A } & 96\end{array}$

289 AGCCTT

$97 \mathrm{~S} \quad \mathrm{~L}$

294

Fig. 2 Nucleotide and amino acid sequences of CAP-Pa28. Underlined amino acid sequences were obtained from $\mathrm{N}$-terminal amino acid sequencing
Induction of HR by recombinant CAP-Pa28

GST-fused recombinant CAP-Pa28 (GST-CAP-Pa28) was overexpressed in E. coli, collected, solubilized, and refolded. The refolded protein was purified by chromatography on a GST-affinity column, and thrombin was used to remove the GST tag while on the column (Fig. 3a). Recombinant GST-CAP-Pa28 and CAP-Pa28 induced HR in the tobacco plant, N. glutinosa (Fig. 3b).

Identification of proteins from $N$. glutinosa that interact with CAP-Pa28

To identify proteins that potentially interact with CAPPa28, we performed a yeast two-hybrid assay. First, the CAP-Pa28 cDNA was fused to the GAL4 DNA-binding domain in the bait vector (pGBKT7). Next, cDNA made by reverse transcription of $N$. glutinosa RNA was used to construct an activation domain (AD) fusion library. Co-transformation of yeast cells with the bait vector, the AD fusion library, and linearized pGADT7-Rec allowed the screening of $5.7 \times 10^{5}$ clones. A total of 358 positive clones were obtained by selection with amino acid dropout medium and an $\mathrm{X}-\alpha$-galactosidase assay (data not shown).

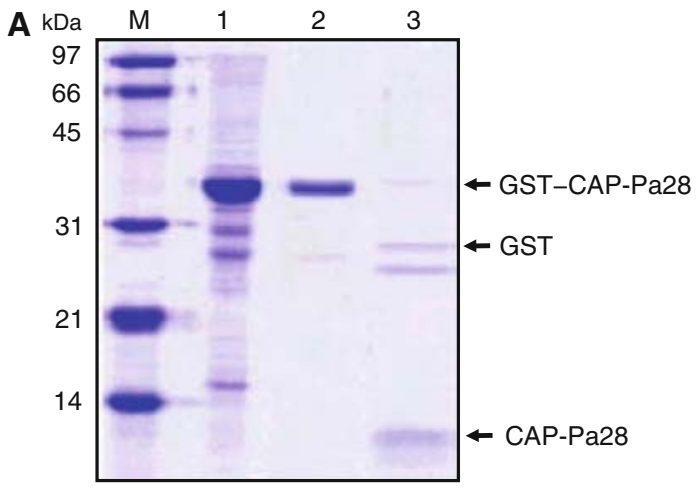

B

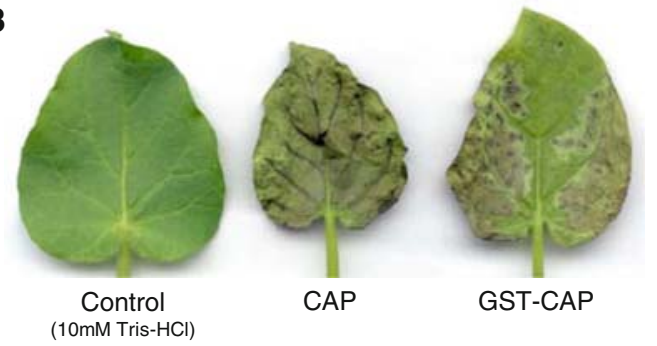

Fig. 3 Purification and the hypersensitive-response activity of recombinant capsicein GST-Cap-Pa28. a SDS-PAGE analysis of GST-Cap-Pa28. M: molecular size markers, 1: solubilized and refolded GST-Cap-Pa28; 2: Purified GST-Cap-Pa28; 3: Cleaved Cap-Pa28, after thrombin treatment. b Induction of the hypersensitive response by GST-Cap-Pa28 in tobacco (Nicotiana glutinosa) leaves. CAP, purified Cap-Pa28 from Phytophthora capsici Pa28; GST-CAP, GST-Cap-Pa28. The hypersensitive response was detected $18 \mathrm{~h}$ after the treatment of $10-50 \mathrm{nmol}$ of protein 
The positive clones were individually isolated and sequenced, and one (pADNG-238) of these clones showed high similarity to the Ser/Thr kinase domain of many plant receptor-like kinases (RLKs). To obtain the full length of this gene for sequencing, RACE was performed.

Isolation of the $N g R L K 1$ and its sequence analysis

The nucleotide sequence of the clone obtained from the yeast-two hybrid assay was determined, revealing a 2,749bp in length with a 2,499-bp ORF encoding a polypeptide of 832 amino acids. This gene was designated $N g R L K 1$. The amino acid sequence of NgRLK1 is $33 \%$ and $27.6 \%$ identical to sequences of RLKs from Arabidopsis thaliana and Oryza sativa, respectively. In addition, NgRLK1 shares sequence similarity with RLKs of Brassica oleracea (26.7\% identity) and Zea mays (24.9\% identity) (Fig. 4a). The calculated molecular mass of NgRLK1 is $93,490 \mathrm{Da}$, and the $\mathrm{pI}$ is 6.67 . The structural features of NgRLK1 are typical of a receptorlike kinase. It is composed of three main domains: a putative extracellular domain, a single transmembrane domain, and a C-terminal cytoplasmic Ser/Thr protein kinase domain. The putative extracellular domain contains an $\mathrm{N}$-terminal signal sequence, a B-lectin domain, an S-locus glycoprotein domain, and a PAN AP domain (Fig. 4b). The transmembrane segment consists primarily of hydrophobic amino acids, and the kinase domain has about $40 \%$ sequence similarity to other plant RLKs. The putative extracellular domain showed a low level of sequence identity (20-25\%), which is considered a determinant factor of ligand specificity [30]. The NgRLK1 sequence has been deposited in GenBank (accession no. FJ217819). In phylogenetic analysis of NgRLK1, NgRLK1 is most closely related to PR5K (PR5like receptor kinase) of A. thaliana [31] (Fig. 5).

A
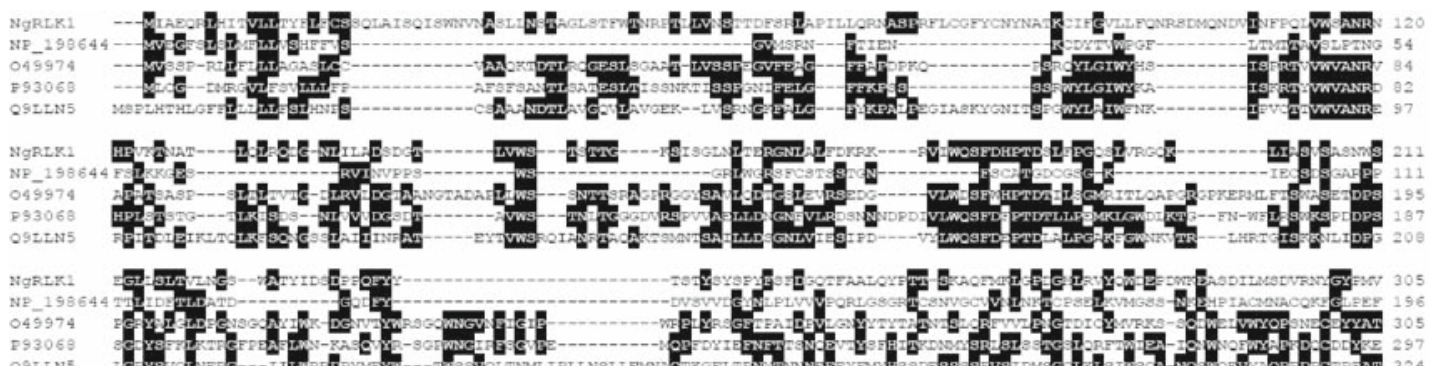

293068 G

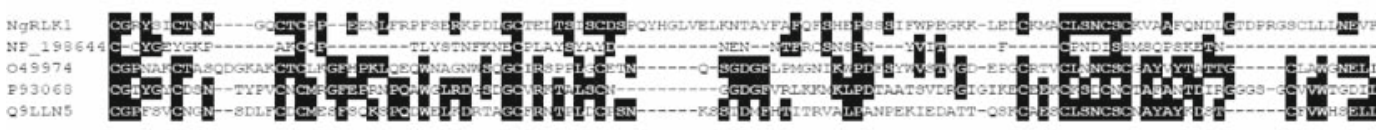

NgLELK1
NF_198644
049974
P93068

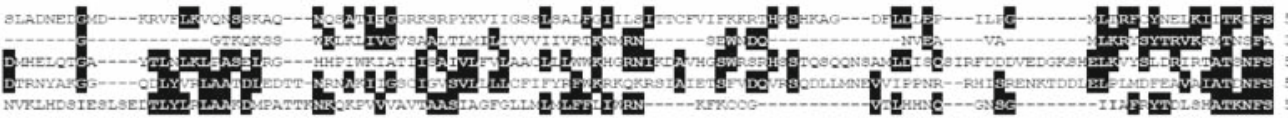

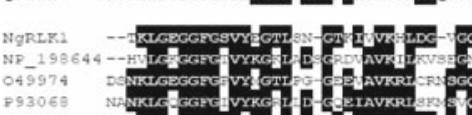

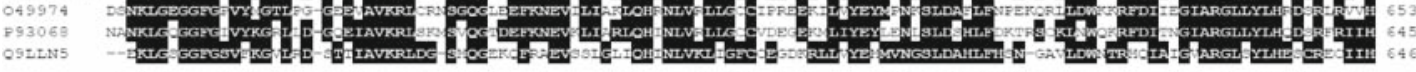

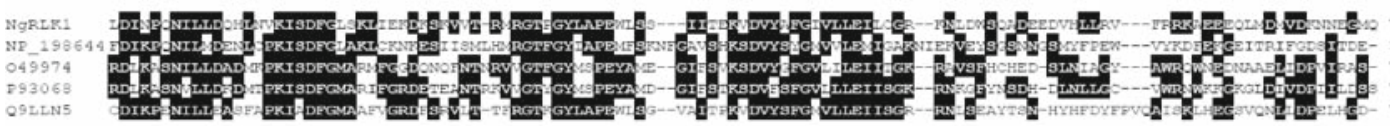

Q9LLN5
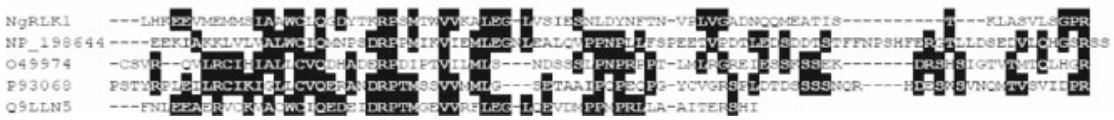

B

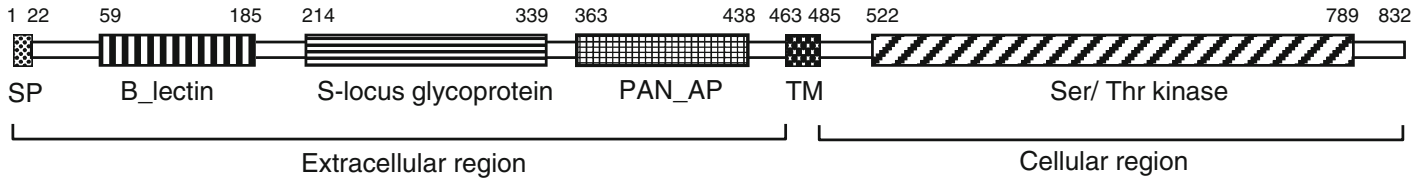

Fig. 4 NgRLK1 amino acid sequence and its predicted domain structure. a Amino acid sequence alignment of $N g R L K 1$ with members of the receptor-like kinase family. Identical amino acids are represented by solid black lines. Spaces indicate gaps introduced to maximize the alignment. The other RLKs are indicated by their
EMBL accession numbers: NP_198644 (Arabidopsis thaliana), O49974 (Zea mays), P93068 (Brassica oleracea), and Q9LLN5 (Oryza sativa). b Schematic representation of NgRLK1 based on a conserved domain analysis. SP, signal peptide; TM, transmembrane 


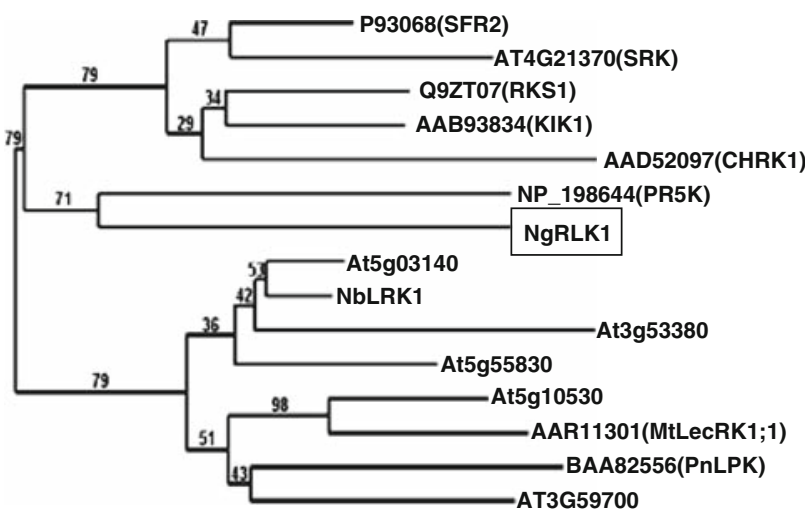

Fig. 5 Phylogenetic tree for the known plant receptor-like kinases (RLKs) including NgRLK1. Maximum likelihood analysis was performed using PhyML program on the Phylogeny.fr server (http://www.phylogeny.fr). The amino acid sequences of plant RLKs were obtained from Genbank. Bootstrap values from 500 bootstrap replicates are shown next to the branches

\section{Interaction of CAP-Pa28 and NgRLK1}

Interaction between CAP-Pa28 and NgRLK1 could be observed when NgRLK1 was used as bait and CAP-Pa28 as prey in a yeast-two hybrid assay (Fig. 6). To identify the domain of NgRLK1 interacting with CAP-Pa28, a binding test of the extracellular and cellular domains of NgRLK1 with CAP-Pa28 was conducted using the yeast-two hybrid assay. Interestingly, the extracellular and cellular domains, respectively, interacted with CAP-Pa28 (Fig. 6). To further confirm the interaction between CAP-Pa28 and NgRLK1, we performed a pull-down assay using purified $\mathrm{His}_{6}{ }^{-}$ NgRLK1 ${ }^{23-438}$ and $\mathrm{His}_{6}-\mathrm{NgRLK} 1^{522-789}$ incubated with immobilized GST or GST-CAP-Pa28. In this assay, $\mathrm{His}_{6}$ NgRLK1 ${ }^{23-438}$ and $\mathrm{His}_{6}-\mathrm{NgRLK} 1^{522-789}$ interacted with GST-CAP-Pa28 but not with GST alone (Fig. 7). These results indicated that CAP-Pa28 can bind directly to the

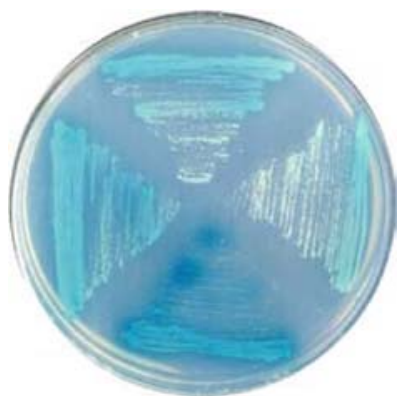

-Ade/-His/-Leu/-Trp/X-a-Gal

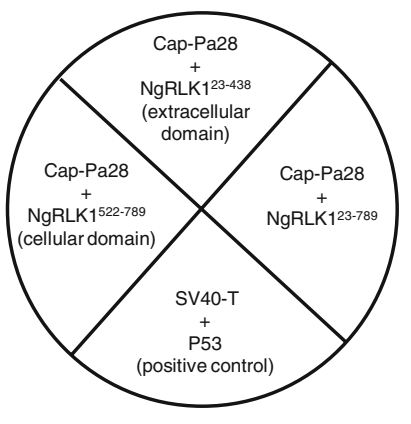

Fig. 6 Protein-protein interaction of the CAP-Pa28 and NgRLK1 domains (yeast-two hybrid assay). Yeast cells harboring the bait and prey plasmid pairs were grown and showed blue color on selective medium lacking Ade, His, Leu, and Trp with $\mathrm{X}-\alpha-\mathrm{Gal}$ at $30^{\circ} \mathrm{C}$. pGBKT7-53 and pGADT7-T were co-transformed into AH109 as positive control extracellular and cellular domains of NgRLK1, which is consistent with the results of the yeast two-hybrid assay.

Autophosphorylation of the kinase domain of NgRLK1

For biochemical studies investigating kinase activity, the kinase domain of NgRLK1 (NgRLK1 ${ }^{522-789}$ ) was expressed as a fusion protein with GST in E. coli (Fig. 8a). In the presence of ATP and $\mathrm{Mn}^{2+}$ or $\mathrm{Mg}^{2+}$, GST-NgRLK1 ${ }^{522-789}$ was autophosphorylated, with higher activity in the presence of $\mathrm{Mn}^{2+}$ (Fig. 8b). GST-NgRLK1 ${ }^{522-789}$ activated by $\mathrm{Mn}^{2+}$ showed a diffuse band and lower mobility than GST-NgRLK $1^{522-789}$ activated by $\mathrm{Mg}^{2+}$ in SDS-PAGE with CBB staining (Fig. 8b).

\section{Discussion}

Although many elicitins from Phytophthora species have been reported, it is not clear whether elicitins contribute directly to Phytophthora pathogenicity. Elicitins trigger a plant defense response in most Nicotiana species, and this response is sufficient to protect against infection by not only Phytophthora but also bacteria, fungi, and viruses [3]. A prominent symptom of the defense response is the hypersensitive response (HR), which results from incompatible interactions between a plant and a pathogen. The HR involves rapid cell death of infected plant tissues and the elaboration of inducible defense proteins. The way in which elicitins induce the HR is puzzling. Elicitins are extracellular proteins, and thus it would seem likely that an elicitin receptor would be located in the plant plasma membrane. Identifying the receptor responsible for the elicitin response is of considerable interest, as most Phytophthora species produce elicitins and therefore an elicitin receptor should confer broad-spectrum Phytophthora resistance [32-34].

In this study, we isolated a gene encoding capsicein CAP-Pa28 from P. capsici Pa28 and identified a capsiceininteracting protein, which is homologous to plant RLKs, from $N$. glutinosa using a yeast two-hybrid assay. RLKs are unusual membrane-associated plant protein kinases, some of which have important roles in pathogen resistance [35]. An RLK comprises a putative extracellular domain, a transmembrane domain, and a protein kinase domain. All RLKs identified in plants thus far have a Ser/Thr kinase domain, in contrast to the tyrosine-specific kinase domain common in animals. NgRLK1 has a domain structure similar to that of plant RLKs. Based on the structure of the putative extracellular domain, Satterlee et al. divided plant receptor kinases into several classes [35]: those with an extracellular domain homologous to S-locus glycoproteins [36], homologous to putative carbohydrate-binding lectins 


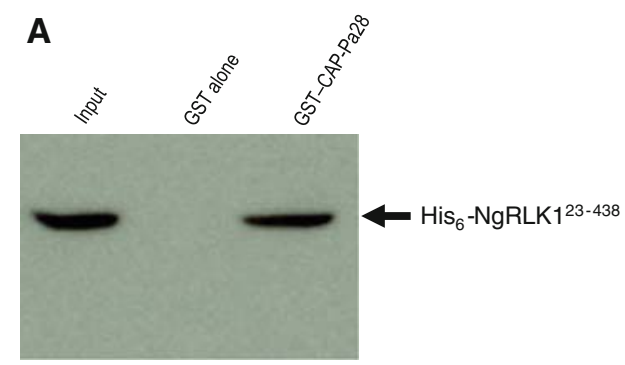

Fig. 7 Direct interaction between CAP-Pa28 and the extracellular and cellular domains of NgRLK1 in vitro (GST-pull-down assay). a GST-pull-down assay to test the binding of $\mathrm{His}_{6}-\mathrm{NgRLK}^{23-438}$ with GST and GST-CAP-Pa28. The arrow indicates the positions of His $_{6}-\mathrm{NgRLK}^{23-438}(48.2 \mathrm{kDa})$. b GST-pull-down assay to test the

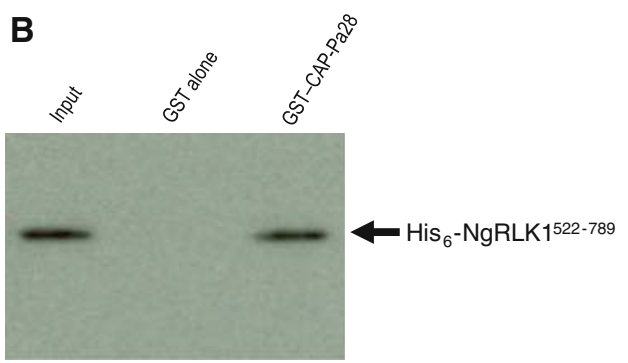

binding of $\mathrm{His}_{6}-\mathrm{NgRLK} 1^{522-789}$ with GST and GST-CAP-Pa28. The arrow indicates the positions of $\mathrm{His}_{6}-\mathrm{NgRLK}^{522-789}(32.6 \mathrm{kDa})$. The bound proteins were eluted, separated by SDS-PAGE, and immunoblotted with anti- $6 \times$ His tagged antibody (Takara)
Fig. 8 Purification and autophosphorylation assay of GST-NgRLK1 ${ }^{522-789}$. a SDS-PAGE analysis of GST-NgRLK1 $1^{522-789}$. M, molecular size markers; 1 , Noninduced; 2, IPTG-induced; 3, Purified GSTNgRLK1 $1^{522-789}$. GSTNgRLK1 $1^{522-789}$ was detected by CBB staining. b autophosphorylation activity of GST-NgRLK1 ${ }^{522-789}$. Autoradiogram (right) and stained gel (left) are shown

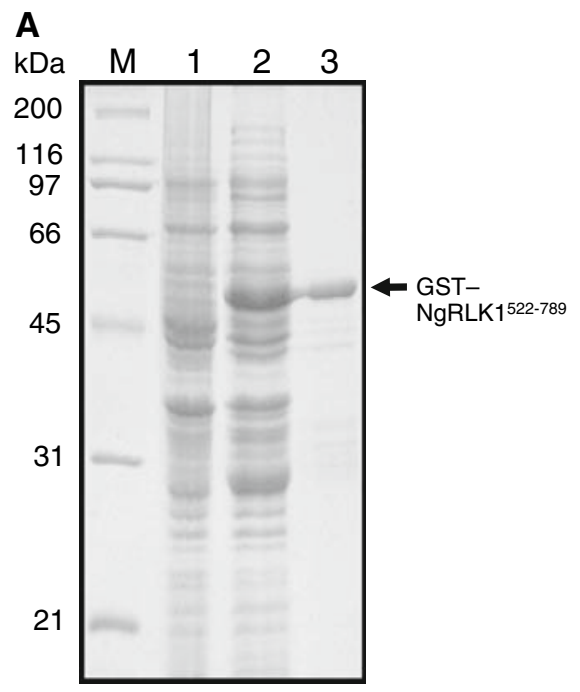

[37], or homologous to pathogenesis-related (PR5) proteins [31]; some RLKs have extracellular domains with a variable number of leucine-rich repeats (LRRs) [38]. Interestingly, the extracellular domain of NgRLK1 contains both lectin-like and S-locus glycoprotein domains, in addition to a PAN AP domain, which is known to mediate proteinprotein or protein-carbohydrate interactions [39]. The domain structure of NgRLK1 is similar to that of the S receptor kinase (SRK) from B. oleracea [40]. It has been shown that SRK mediates the self-incompatibility response in Brassicaceae [41]. Recently, Kanzaki et al. reported on NbLRK1, which is a lectin-like receptor kinase protein of $N$. benthamiana that interacts with INF1 elicitin of $P$. infestans [23]. NbLRK1 plays an important role in triggering the INF1-mediated HR signal downstream. Kanzaki et al. also demonstrated that INF1 binds to the intracellular kinase domain of NbLRK1 in a yeast-two hybrid assay. This result suggested that plant recognition of INF1 takes place inside the plant cells. Unlike NbLRK1, extracellular NgRLK1 was found to interact with CAPPa28 in yeast-two hybrid and GST-pull-down assays, and the structure of the NgRLK1 extracellular domain suggests possible interactions with proteins or carbohydrates. This evidence supported a direct interaction of the extracellular domain of NgRLK1 with CAP-Pa28. Interestingly, CAP$\mathrm{Pa} 28$ was also found to bind to the intracellular kinase domain of NgRLK1. Kanzaki et al. proposed that the INF1 protein could be transported inside plant cells by endocytosis or an unknown mechanism to interact with the kinase domain of NbLRK1 [23]. Based on that report and our findings, we speculate that plant recognition of CAP-Pa28 occurs in the extracellular and intracellular spaces. To support this hypothesis, plant cell localization of CAPPa28 should be confirmed.

In protein-based phylogenetic analysis, NgRLK1 was more closely related to PR5K from A. thaliana than to the lectin-like receptor kinases, which include NbLRK1, and other plant RLKs. Wang et al. suggested that PR5K receptor is involved in the perception of microbial signals [31]. The analysis of phylogenetic and domain-structure of NgRLK1 implies that NgRLK1 might play a role as receptor for pathogen-derived signal molecules like 
elicitins, and we propose that NgRLK1 is a new type of plant RLK that recognize Cap-Pa28.

The recombinant Ser/Thr kinase domain of NgRLK1 had autophosphorylation activity, and this activity was higher with $\mathrm{Mn}^{2+}$ than with $\mathrm{Mg}^{2+}$, as previously reported for other plant RLKs [42-44]. Compared with GST-NgRLK1 ${ }^{522-789}$ activated by $\mathrm{Mg}^{2+}$, GST-NgRLK1 $1^{522-789}$ activated by $\mathrm{Mn}^{2+}$ gave a more diffuse band of lower mobility on SDSPAGE, suggesting that GST-NgRLK1 $1^{522-789}$ undergoes a conformational change upon enzymatic activation. This result shows that $N g R L K 1$ encodes an active protein kinase and raises the possibility that NgRLK1 is involved in the HR signaling pathway in $N$. glutinosa.

Southern blot analysis indicated that there is more than one copy of NgRLK1 in N. glutinosa (Y. T. Kim, unpublished data), whereas it has been reported that RLKs from Petunia inflata, B. napus, and Catharanthus roseus exist only as single copies [42, 45, 46].

Here, we report using a yeast-two hybrid assay to isolate a plant RLK based on its interaction with capsicein. We propose that NgRLK1 represents a new kind of plant RLK and is a potential capsicein receptor. To verify this, it will be necessary to determine whether NgRLK1 functions as a capsicein receptor in vivo. The data presented in this study contribute to an understanding of the biochemical and physiological functions of plant RLKs and the mechanism of the elicitin-induced defense response. These findings may have important implications for the molecular breeding of disease-resistance in crops.

Acknowledgments This work was supported by a grant from the National Institute of Agricultural Biotechnology, Rural Development Administration, Republic of Korea. We thank Dr. H. J. Jee (Rural Development Administration) for providing the Phytophthora capsici used in this study.

Open Access This article is distributed under the terms of the Creative Commons Attribution Noncommercial License which permits any noncommercial use, distribution, and reproduction in any medium, provided the original author(s) and source are credited.

\section{References}

1. Barksdale TH, Papavizas GC, Johnston SA (1984) Resistance to foliar blight and crown rot of pepper caused by Phytophthora capsici. Plant Dis 68:506-508. doi:10.1094/PD-69-506

2. Hwang BK, Kim CH (1995) Phytophthora blight of pepper and its control in Korea. Plant Dis 79:221-226

3. Tyler BM (2002) Molecular basis of recognition between Phytophthora pathogens and their hosts. Annu Rev Phytopathol 40:137-167. doi:10.1146/annurev.phyto.40.120601.125310

4. Nespoulous C, Huet JC, Pernollet JC (1992) Structure-function relationships of $\alpha$ and $B$ elicitins, signal proteins involved in the plant-Phytophthora interaction. Planta 186:551-557. doi: 10.1007/BF00198035
5. Ricci P, Bonnet P, Huet JC et al (1989) Structure and activity of proteins from pathogenic fungi Phytophthora eliciting necrosis and acquired resistance in tobacco. Eur J Biochem 183:555-563. doi:10.1111/j.1432-1033.1989.tb21084.x

6. Sasabe M, Takeuchi K, Kamoun S et al (2000) Independent pathways leading to apoptotic cell death, oxidative burst and defense gene expression in response to elicitin in tobacco cell suspension culture. Eur J Biochem 267:5005-5013. doi: 10.1046/j.1432-1327.2000.01553.x

7. Kamoun S (2006) A catalogue of the effector secretome of plant pathogenic oomycetes. Annu Rev Phytopathol 44:41-46. doi: 10.1146/annurev.phyto.44.070505.143436

8. Kamoun S, Klucher KM, Coffey MD et al (1993) A gene encoding a host-specific elicitor protein of Phytophthora parasitica. Mol Plant Microbe Interact 6:573-581

9. Panabieres F, Marais A, Le Berre JY et al (1995) Characterization of a gene cluster of Phytophthora cryptogea which codes for elicitins, proteins inducing a hypersensitive-like response in tobacco. Mol Plant Microbe Interact 8:996-1003

10. Mao Y, Tyler BM (1996) Cloning and sequence analysis of elicitin genes of Phytophthora sojae. Fungal Genet Biol 20:169172. doi:10.1006/fgbi.1996.0031

11. Becker J, Nagel S, Tenhaken R (2000) Cloning, expression and characterization of protein elicitors from the soyabean pathogenic fungus Phytophthora sojae. J Phytopathol 48:161-167. doi: 10.1046/j.1439-0434.2000.00053.x

12. Kamoun S, Lindqvist H, Govers F (1997) A novel class of elicitin-like genes from Phytophthora infestans. Mol Plant Microbe Interact 10:1028-1030. doi:10.1094/MPMI.1997.10.8.1028

13. Duclos J, Fauconnier A, Coelho AC et al (1998) Identification of an elicitin gene cluster in Phytophthora cinnamomi. DNA Seq 9:231-237. doi:10.3109/10425179809105210

14. Kamoun S, Young M, Glascock CB et al (1993) Extracellular protein elicitors from Phytophthora: host-specificity and induction of resistance to bacterial and fungal phytopathogens. Mol Plant Microbe Interact 6:15-25

15. Pernollet JC, Sallantin M, Salle-Tourne M et al (1993) Elicitin isoforms from seven Phytophthora species: comparison of their physico-chemical properties and toxicity to tobacco and other plant species. Physiol Mol Plant Pathol 42:53-67. doi:10.1006/ pmpp.1993.1005

16. Nespoulous C, Pernollet JC (1994) Local structural differences between alpha- and beta elicitins shown by circular dichroism and ultraviolet difference spectroscopy. Int J Protein Res 43:154-159

17. Heut JC, Le Caer JP, Nespoulous C et al (1995) The relationships between the toxicity and the primary and secondary structures of elicitinlike protein elicitors secreted by the phytopathogenic fungus Pythium vexans. Mol Plant Microbe Interact 8:302-310

18. Jiang RH, Tyler BM, Whisson SC (2005) Ancient origin of elicitin gene clusters in Phytophthora genomes. Mol Biol Evol 23:338-351. doi:10.1093/molbev/msj039

19. Kamoun S, Young M, Forster H et al (1994) Potential role of elicitins in the interaction between Phytophthora species and tobacco. Appl Environ Microbiol 60:1593-1598

20. Wendenhenne D, Binet MN, Blein JP et al (1995) Evidence for specific, high-affinity binding sites for a proteinaceous elicitor in tobacco plasma membrane. FEBS Lett 374:203-207. doi: 10.1016/0014-5793(95)01108-Q

21. Lochman J, Kasparovsky T, Damborsky J et al (2005) Construction of cryptogein mutants, a proteinaceous elicitor from Phytophthora, with altered abilities to induce a defense reaction in tobacco cells. Biochemistry 44:6565-6572. doi:10.1021/bi0502285

22. Mikes V, Milat ML, Ponchet M et al (1997) The fungal elicitor cryptogein is a sterol carrier protein. FEBS Lett 416:190-192. doi:10.1016/S0014-5793(97)01193-9 
23. Kanzaki H, Saitoh H, Takahashi Y et al (2008) NbLRK1, a lectinlike receptor kinase protein of Nicotiana benthamiana, interacts with Phytophthora infestans INF1 elicitin and mediates INF1induced cell death. Planta 228:977-987. doi:10.1007/s00425-0080797-y

24. Sambrook J, Russell BW (2001) Molecular cloning: a laboratory manual, 3rd edn. Cold Spring Harbor Laboratory Press, Cold Spring Harbor

25. Baillieul F, de Ruffray P, Kauffmann S (2003) Molecular cloning and biological activity of $\alpha$-, $\beta$-, and $\gamma$-megaspermin, three elicitins secreted by Phytophthora megasperma H20. Plant Physiol 131:155-166. doi:10.1104/pp.012658

26. Schultz J, Milpetz F, Bork P et al (1998) SMART, a simple modular architecture research tool: Identification of signaling domains. Proc Natl Acad Sci USA 95:5857-5864. doi:10.1073/ pnas.95.11.5857

27. Letunic I, Copley RR, Pils B et al (2006) SMART 5: domains in the context of genomes and networks. Nucleic Acids Res 34:257260. doi:10.1093/nar/gkj079

28. Lebrun-Garcia A, Ouaked F, Chiltz A et al (1998) Activation of MAPK homologues by elicitors in tobacco cells. Plant J 15:773781. doi:10.1046/j.1365-313X.1998.00269.x

29. Huet JC, Pernollet JC (1989) Amino acid sequence of cinnamomin, a new member of the certain family, and its comparison to cryptogein and capsicein. FEBS Lett 257:302-306. doi: 10.1016/0014-5793(89)81557-1

30. Braun DM, Walker JC (1996) Plant transmembrane receptors: new pieces in the signaling puzzle. Trends Biotechnol 21:70-73

31. Wang X, Zafian P, Choudhary M et al (1996) The PR5K receptor protein kinase from Arabidopsis thaliana is structurally related to a family of plant defense proteins. Proc Natl Acad Sci USA 93:2598-2602. doi:10.1073/pnas.93.6.2598

32. Yu LM (1995) Elicitins from Phytophthora and basic resistance in tobacco. Proc Natl Acad Sci USA 92:4088-4094. doi:10.1073/ pnas.92.10.4088

33. Tepfer D, Boutteaux C, Vigon C et al (1998) Phytophthora resistance through production of a fungal protein elicitor ( $\beta$-Cryptogein) in tobacco. Mol Plant Microbe Interact 11:64-67. doi: 10.1094/MPMI.1998.11.1.64

34. Keller H, Pamboukdjian N, Ponchet M et al (1999) Pathogeninduced elicitin production in transgenic tobacco generates a hypersensitive response and nonspecific disease resistance. Plant Cell 11:223-235
35. Satterlee JS, Sussman MR (1998) Unusual membrane-associated protein kinases in higher plants. J Membr Biol 164:205-213. doi: $10.1007 / \mathrm{s} 002329900406$

36. Nasrallah JB, Nasrallah ME (1993) Pollen-stigma signaling in the sporophytic self-incompatibility response. Plant Cell 6:709-721

37. Herve C, Dabos P, Galaud JP et al (1996) Characterization of an Arabidopsis thaliana gene that defines a new class of putative plant receptor kinases with an extracellular lectin-like domain. J Mol Biol 258:778-788. doi:10.1006/jmbi.1996.0286

38. Torii KU, Mitsukawa N, Oosumi T et al (1996) The Arabidopsis ERECTA gene encodes a putative receptor protein kinase with extracellular leucine-rich repeats. Plant Cell 8:735-746

39. Tordai H, Banyai L, Patthy L (1999) The PAN module: the $\mathrm{N}$-terminal domains of plasminogen and hepatocyte growth factor are homologous with the apple domains of the prekallikrein family and with a novel domain found in numerous nematode proteins. FEBS Lett 12:63-67. doi:10.1016/S0014-5793(99)01 416-7

40. Shiu SH, Bleecker AB (2001) Plant receptor-like kinase gene family: diversity, function, and signaling. Sci STKE 113:re22

41. McCubbin AG, Kao TH (2000) Molecular recognition and response in pollen and pistil interactions. Annu Rev Cell Dev Biol 16:333-364. doi:10.1146/annurev.cellbio.16.1.333

42. Schulze-Muth P, Irmler S, Schroder G et al (1996) Novel type of receptor-like protein kinase from a higher plant (Catharanthus roseus): cDNA, gene, intramolecular autophosphorylation, and identification of a threonine important for auto- and substrate phosphorylation. J Biol Chem 271:26684-26689. doi:10.1074/ jbc.271.43.26684

43. Schaller GE, Bleecker JC (1993) Receptor-like kinase activity in membranes of Arabidopsis thaliana. FEBS Lett 333:306-310. doi:10.1016/0014-5793(93)80676-L

44. Horn MA, Walker JC (1994) Biochemical properties of the autophosphorylation of RLK5, a receptor-like protein kinase from Arabidopsis thaliana. Biochim Biophys Acta 1208:65-74

45. Silva NF, Christie LN, Mazzurco M et al (2001) Characterization of a novel Brassica napus kinase, BNK1. Plant Sci 160:611-620. doi:10.1016/S0168-9452(00)00426-X

46. Skirpan AL, McCubbin AG, Ishimizu T et al (2001) Isolation and characterization of kinase interacting protein 1 , a pollen protein that interacts with the kinase domain of PRK1, a receptor-like kinase of petunia. Plant Physiol 126:1480-1492. doi:10.1104/pp. 126.4.1480 